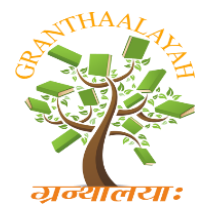

Arts

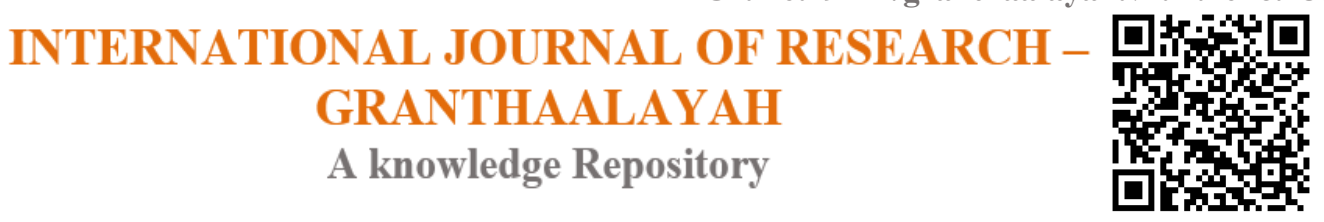

\title{
DEPICTION OF YOGIC PRACTICES IN INDIAN ART
}

\author{
Dr. Anjali Pandey *1 \\ ${ }^{* 1}$ Assistant Professor (Drawing \& Painting), Govt. M.L.B. Girls P.G. College, Bhopal, INDIA
}

\begin{abstract}
Art has spectrum of expression that extends. Many sculptures and paintings convey the specific meaning and contents of Yoga. It occupied the distinct, one and only and unparalleled recognition for mental, physical moral and spiritual enhancement. The acceptance of yoga for ultimate achievement in life was inherent tradition "Yoga was one of the Fundamental doctrines devoted to the means to attain perfect health and mental poise"

In the language of Indian art, the depiction of Yog Mudras, Asanas and Postures are employed as idioms to deepen the content and to enrich the meaning It is also the language of gesture which is unique, it works differently. The monastic abstraction, the eternal values the calmness of mind and the transcendent states of experience are perfectly reflected in Indian art work.

In the cultural history of India, Yoga occupied the distinct, one and only and unparalleled recognition for mental, physical moral and spiritual enhancement. The acceptance of yoga for ultimate achievement in life was inherent tradition "Yoga was one of the Fundamental doctrine devoted to the means to attain perfect health and mental poise.
\end{abstract}

Keywords:

Indian Art, sculptures and paintings, Yoga.

Cite This Article: Dr. Anjali Pandey, "DEPICTION OF YOGIC PRACTICES IN INDIAN ART" International Journal of Research - Granthaalayah, Vol. 4, No. 1 (2016): 199-205.

\section{INTRODUCTION}

The cybernetic vision of human personality visualize into many strata. In the cultural history of India, Yoga occupied the distinct, one and only and unparalleled recognition for mental, physical moral and spiritual enhancement. The acceptance of yoga for ultimate achievement in life was inherent tradition of India.

"Yoga was one of the Fundamental doctrines devoted to the means to attain perfect health and mental poise" It is the most practical preparation for any undertaking. It is a rich

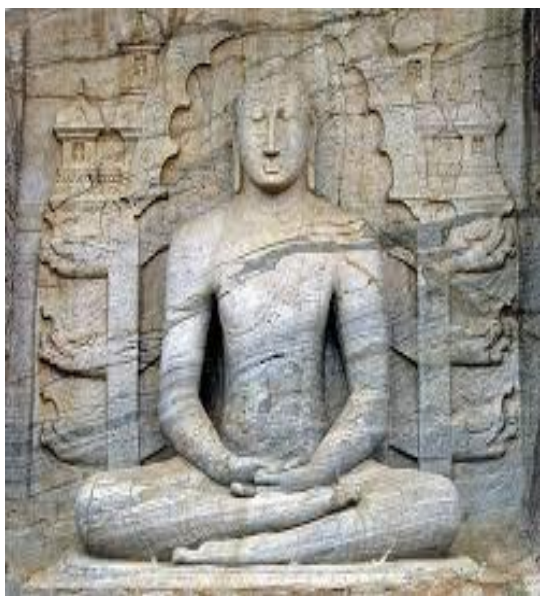


philosophical path which suggests the way of life. There are abundant literary parallels with the concept of 'Art as Yoga'.

The Indian religious principles preach that the path of devotion is the path of love and total surrender. The worship of god and deity through Yoga is not only a spiritual enhancement it is also a path of self- restraint, salvation and performed meditation ${ }^{2}$ The various kind of asceticism both physical and mental is much discussed through Yoga. In Indian art, the calmness of mind, the eternal values, the transcend status of experiences are conveyed in significant and designed language. ${ }^{3}$

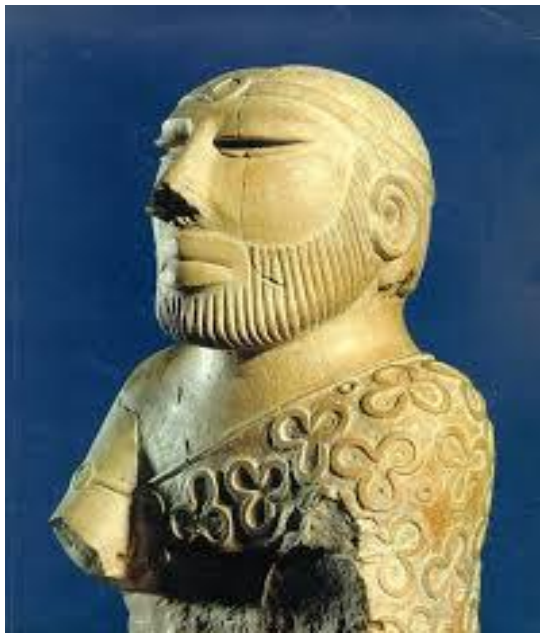

Figure 1: Yogi

(Indus Valley Civilization)

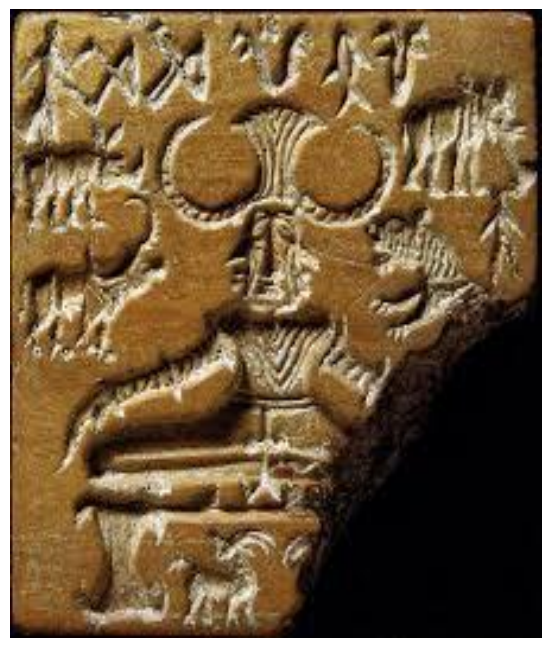

Figure 2: Pashupati in meditation posture; seal; (Indus Valley Civilization)

Many sculptures and paintings convey the specific meaning and contents of Yoga. Art has spectrum of expression that extends. It is also the language of gesture which is unique, it works differently.

The cultural history of Indian Yoga occupied the distinct, one and only and enhancement. The art of living has been in vogue from thousands of years. The treasure of art contains the Integral part of ancient civilization and blossomed as diverse tradition of religion with intrinsic vitality. $^{4}$

The bust portrait of bearded Yogi from Mohenjodaro Pakistan justifies very long continuation of Yoga, and several seals excavated from Indus Valley Civilization dating 3000-1500 B.C. the figures are in position of common Yoga or meditation posture. ${ }^{5}$ Several features of Indus Valley are also found. Seated figure of a Yogi surrounded by a rhino, tiger, elephant and a bull is probably Pashupati probably. In later art of historical period, a three headed figure in Padmasana is notable.

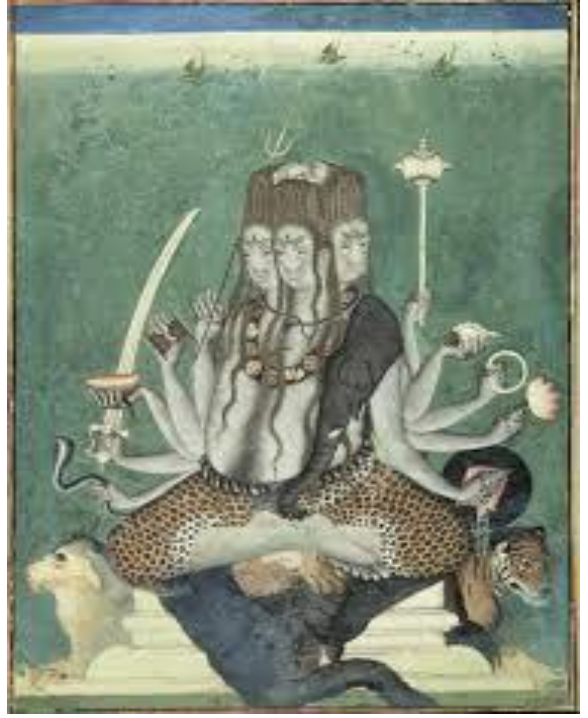

Figure 3: Yogi Shiv (Painting) 
"Gestures, postures and attributes are not only very characteristic feature of Indian works of art but they are also significant conventions designed to convey specific meaning and enhance the content of given form." In Indian art work many significant and specific meaning are conveyed by gestures, and posture. ${ }^{6}$

Anand Coomar Swamy said "Art contains in itself in the deepest principles of life the truest guide to the greatest art the Art of living." There is no stipulated system or principle to read and understand the visual language of art. In the analysis part of it we relate the things according to our previous knowledge of similar or dissimilar presentation stored up in a memory.

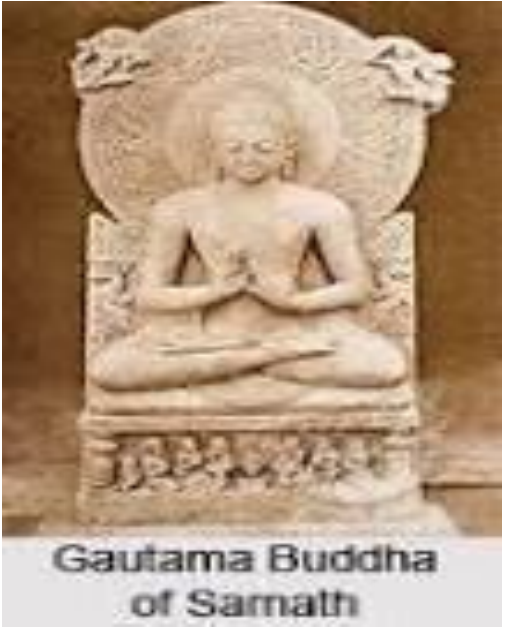

Figure 4: Darmachakra-mudra

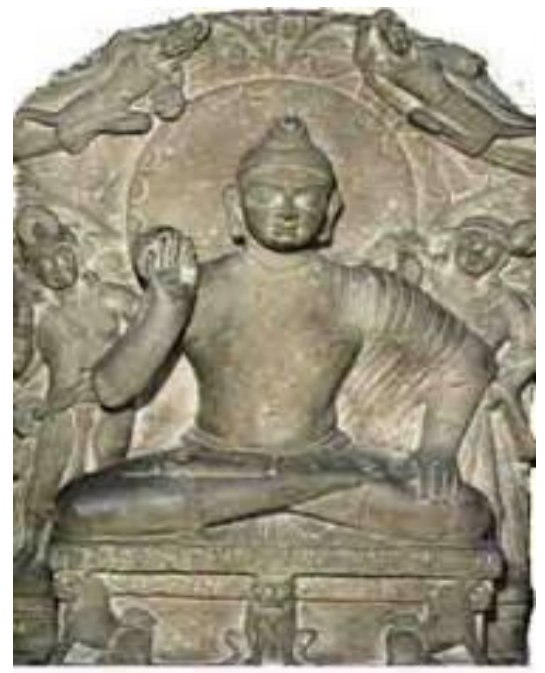

Seated Buddha, Katra Mount, Mathura

Figure 5: Abhaya-mudra In the language of Indian art, the depiction of Yog-Mudras, Asanas and Postures are employed as idioms to deepen the content and to enrich the meaning. 7 .

The Indian art tradition has unbroken hierarchy. It has few parallels in the world where the antiquity, diversity, its depth and breadth could be seen. It has the spectrum of expression which is in one side pure signatory abstraction and on other side visual metaphor. It works differently at each level, from simplicity to sophisticate technology. ${ }^{8}$

The art always provides vigor and vitality to human beings. It is believed that instinct of human being with perception created the art of gesture which with the passage of time took place in art.

The uses of mudras are in existence as a significant sign language before $6^{\text {th }}$ century B.C. ${ }^{9}$ 'Mudras' are also in features as 'divya kriya' (divine action)-"the language of god". In ancient India, the proficiency of a person is considered with the art and culture. In Hindu scripture the term' Yoga' appeared in Upanishad. Upanishad reflects the contemplative tradition. ${ }^{10}$

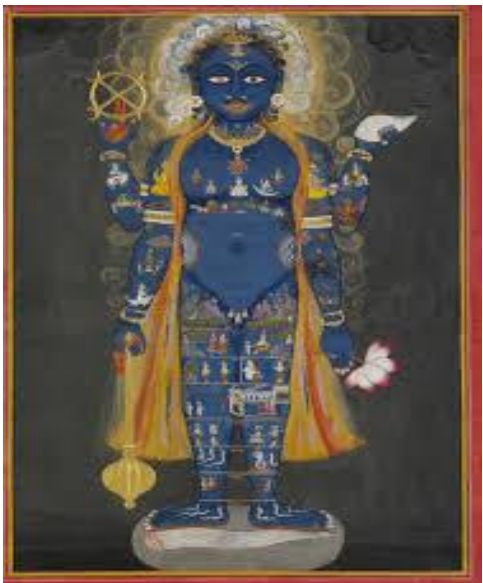

Figure 6: Painting

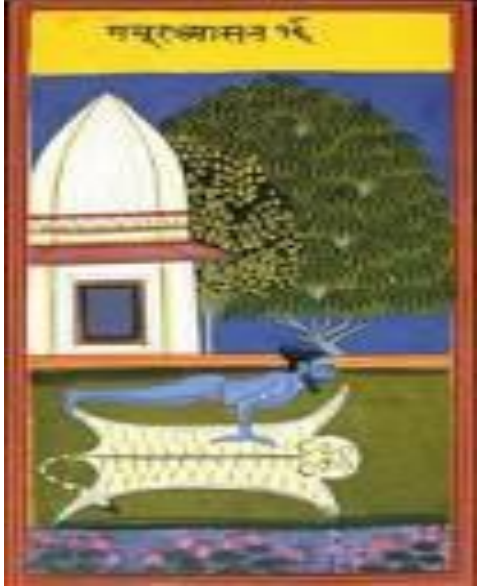

Figure 7: Painting 
In Buddhism the cessation of mental activity and the attaining of "supreme states" arose. It is said that Buddha himself was proficient in this art. The usual posture in which Buddha seated is the posture of contemplation or Vajra asana (the adamantine seat) hands are in 'Dhyanmudra'. Mudras are the developed forms of asanas. ${ }^{11}$ There are several other postures and mudras are depicted in Indian painting and sculpture, in which Buddha is seated Dharma Chakra Mudra, Abhaya Mudra, and Bhumisparsh Mudra, are some of them which often represented as a mark of significance in Buddha figure. ${ }^{12}$

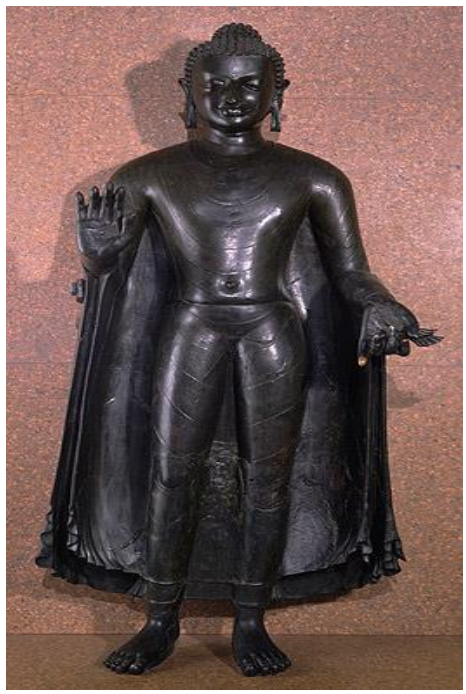

Figure 8: Standing Buddha

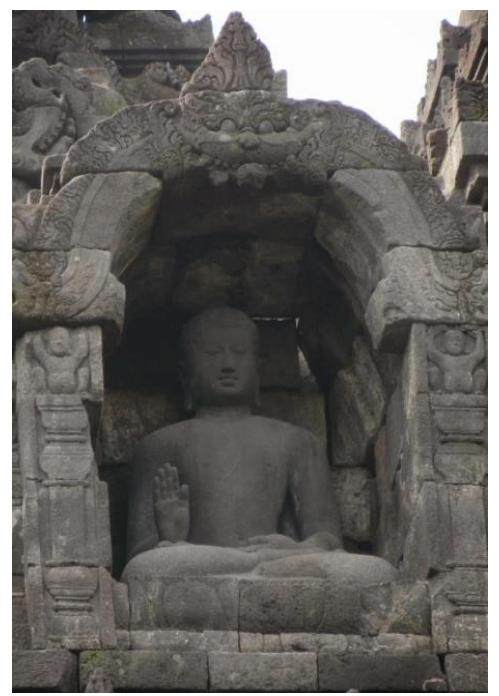

Figure 9: Abhaya-mudra (Jawa Borobudur)

Indian Culture was implanted over a very large part of Asia. Buddhism spread on Central Asia Nepal, Sri-Lanka, Japan, China, Siam, Burma, Bali, Java and Cambodia. The seated Buddha figure symbolizes the dynamic inner power and embodies all the peace that is Buddhism. The Bhagvad Gita introduces distinction of Gyan Yoga (knowledge based Yoga) and Karma Yoga (action based Yoga) Indian pictorial and sculptural art conveys them with specific meaning and contents. $^{13}$

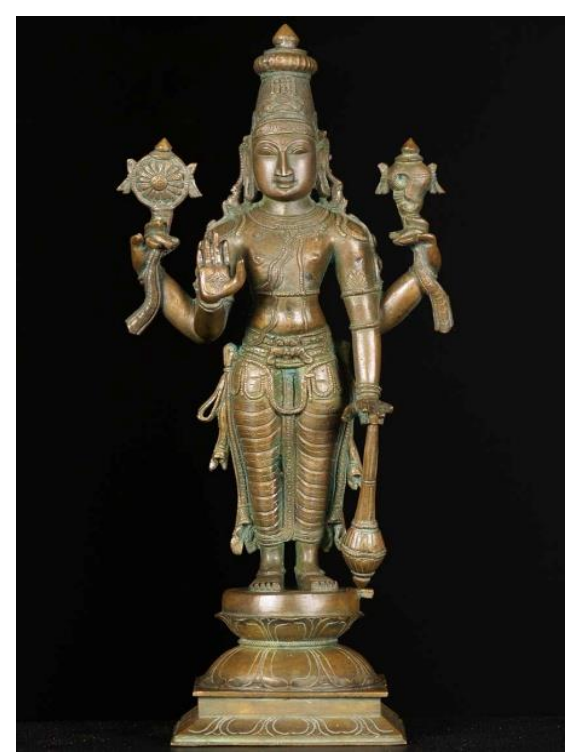

Figure 10: Vishnu (bronze)

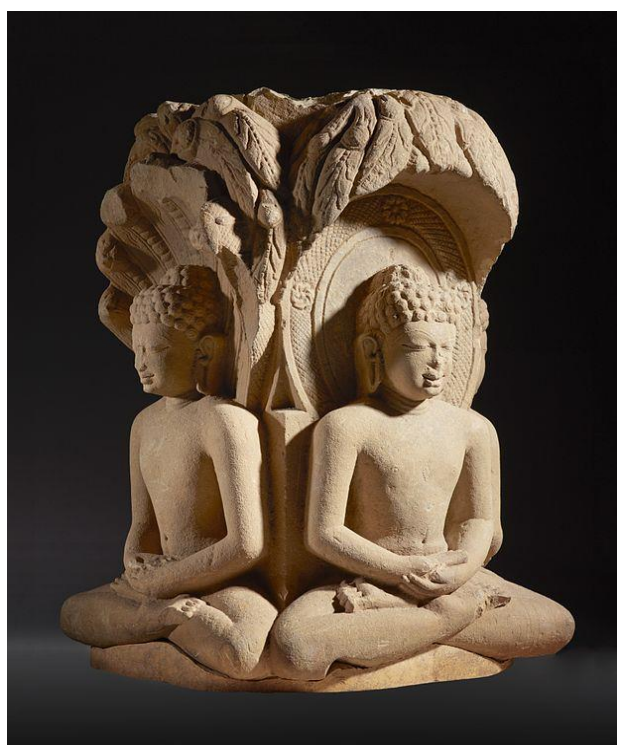

Figure 11: Tirthankar (Adinath Parsvanath Rishabhanath) 
Yoga is originated in India as Marcel arts. Yoga is soul of the Marcel art. It is said in Mahabharata, the Krishna preaches the Arjun about Yoga kriya "Yogh karmeshu koshlam" and make up his mind for 'karma yudha'. The Bhagvad Gita itself considered as a great YogShastra. "samatv yog uchyate". To control our emotions in happiness and sorrows is yoga . 14

In Chitra Sutra, it is described that the artist should follow the rules of body posture, asanas, breathing control or pranayam etc to improve his art work.

The treasure of art contains the integral part of ancient civilization and blossomed as diverse traditions of religions with intrinsic vitality. The monastic abstraction, the eternal values the calmness of mind and the transcendent states of experience are perfectly reflected in Indian art work.

Form is more powerful than sound what the eyes see creates a greater impression than what the ears hear. On the basis of this distinction art, the higher level of culture, scale of values, man's judgment conceptualization, monistic abstraction depicted in form of archetypes in Indian art. It helps people to connect and to socialize with the high morals.

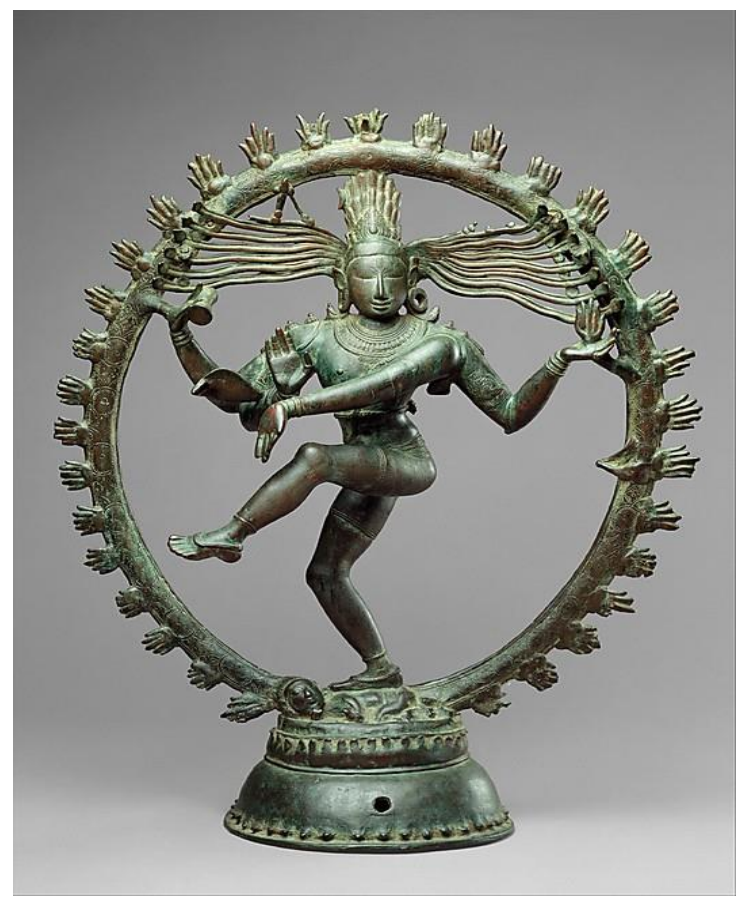

\section{REFERENCES}

Figure 12: Natraj

[1] Coomarswami A.K, The Dance of Shiva ; Bombay Calcutta ; 1956 Pg 44-49.

[2] Iyer K.Bharatha, Pg.18-20.

[3] Subramanian K.G, Moving Focus Pg 95.

[4] Iyer K.Bharatha, Ibid Pg21.

[5] Gairola Vachaspati, Bhartiya Sanskriti Aur Kala Pg111.

[6] Iyer, Pg18-20.

[7] Ibid, $\operatorname{Pg} 21$. 
[8] Subramanian K.G., Moving Focus Pg 95.

[9] Iyer, Pg21.

[10] Wikipedia

[11] Iyer, Pg13-25.

[12] Agrwal V.S., Bhartiya Kala; Varanasi 1977 Pg 248-249.

[13] Saini Vinita, Jain Kamini Manav Jeevan Par Yog ka Prabhav: Research link; 27 VolV (2);2006 Pg-!52.

[14] Ibid. 